\title{
In-house validation of a lamp kit for diagnosis of Plasmodium, Plasmodium falciparum and Plasmodium vivax in Vietnam
}

\author{
Nguyen Thi Hong Ngoc, Nguyen Thi Huong Binh, Nguyen \\ Van Hong, Ngo Duc Thang, Nguyen Thu Huong* and Tran \\ Thanh Duong
}

National Institute of Malariology, Parasitology and Entomology, Hanoi, Vietnam

Received: 15 July, 2020

Accepted: 28 July, 2020

Published: 29 July, 2020

*Corresponding author: Nguyen Thu Huong, National Institute of Malariology, Parasitology and Entomology, Hanoi, Vietnam, E-mail: huong.nimpe.vn@gmail.com

Keywords: Plasmodium; LAMP; Green malachite

https://www.peertechz.com

Check for updates

\section{Abstract \\ Vietnam announced the elimination of malaria in 25 provinces in 2019 and and advance to eliminate malaria nationwide by 2030 . Quick, accurate diagnosis and prompt treatment play a very important role in malaria eradication strategies. In this study, we developed the LAMP technique to detect $P$ lasmodium spp., $P$. falciparum, $P$. vivax from different kinds of sample such as whole blood, dried blood spot, etc. The advantages of this method included high specificity, fast detection time, and simple equipment use. Primer set was designed for founding on 18S rRNA gene. A positive reaction was visualised with the naked eye, using the color indicator, Malachite Green.}

\section{Introduction}

Up to day, Malaria is still considered as a public health problem in tropical and subtropical regions. In 2018, there were approximately 228 million estimated cases of malaria identified globally [1]. According to a report of the national malaria prevention program, in 2019 Vietnam had 4,665 malaria parasites detected by cyanoscopy reduced $3.08 \%$ compared to 2018. Rate of parasite / 1,000 people was 0.048 . The number of malaria cases gradually decreased through 10-year period from 2010 to 2019. In 2019 malaria patients decreased by $89.16 \%$ compared to 2010. Malaria parasites concentrated mainly in the Central and Central Highland provinces. The number of malaria parasites may be lower than they actually are, due to the presence of asymptomatic malaria and the low density of parasites below the detection threshold of a microscope; According to some unpublished reports in Vietnam, this rate can reach $30-50 \%$ [2]. Currently, there are three main groups of methods applied in the diagnosis of malaria parasites: Giemsa stained blood smear, rapid diagnostic test (based on immune method), Molecular biology techniques like PCR, Real time-PCR [3]. Giemsa-stained smear test is still the gold standard in the confirmed diagnosis of malaria case [4]. This method is widely used, most popular in many countries around the world, with an average detection threshold of about 50 - 100 parasites/uL of blood from all Plasmodium spp, low test costs, performed even in laboratory conditions and field testing [1]. However, this method is difficult to detect cases with low parasite density, the testing staff must trained, must be retrained regularly, especially in areas with low prevalence of malaria or eliminate areas where there is little opportunity for testing [5-7]. Rapid diagnostic tests (RDTs) are also widely used, especially in areas where microscopy sites have not yet been available, but RDTs still have limitations such as low parasite detection threshold, false positive rate, and long positive time $[5,7,8]$. The common disadvantage of these two methods is the low threshold for detection of malaria parasites $[9,10]$. Therefore, it is estimated that a large number of people with low-density parasite infection are not detected. According to WHO (2014), people carrying low-density parasites below detection threshold of GSB and RDTs may be responsible for contributing $20-50 \%$ of the pathogen to malaria vector and vice versa [10]. Molecular biology techniques based on DNA analysis have proven to be more sensitive and specific than microscopic 
detection or rapid test (RDTs) [4]. In particular, traditional PCR techniques such as Nested-PCR, Seminested MultiplexPCR based on the target gene of $18 \mathrm{~S}$-rRNA are widely applied in the diagnostic studies of malaria for high sensitivity and specificity [11-13]. The detection was determined to be between 1-5 parasites $/ \mu$ l of blood [13]. The Real time-PCR technique has a high sensitivity at the LOD $>0.5 \mathrm{KST} / \mu \mathrm{l}$ of blood [14]. However, current DNA amplification techniques are timeconsuming, complex and not field-friendly.

To eliminate malaria globally, strategic measures are needed to increase the ability to detect sources of disease. The technical limitations of current testing methods, which requires the development of a highly sensitive diagnostic kit which has a detection threshold comparable to that of DNA amplification techniques in the laboratory, but requires no expensive equipment, faster testing times, is easy for training and can be done in the field. The LAMP technique is a molecular biology technique that uses heat to amplify single strands of DNA, first described by Notomi, et al. [15]. The method has a high amplification efficiency in 15-60 minutes [15]. And then Han ET, et al. [16], developed LAMP to detection of four Plasmodium species for clinical diagnosis [16]. Imai Kazuo, et al. (2017) reported the novel diagnostic method for malaria using LAMP and MinION ${ }^{\mathrm{TM}}$ nanopore sequencer [17]. Jaymin C, et al. (2013) developed the RealAmp technique, a LAMP technique combined with real-time isotherms to quickly detect malaria parasites. This study also built a primer pair to detect P. vivax by RealAmp method [18]. Compared with other molecular methods such as PCR, real time PCR ..., LAMP has the advantage of having similar accuracy, simple implementation, especially short execution time and can detect results by naked eye $[11,19-22]$. Therefore, LAMP is often used to create quick diagnostic kits which are widely popular in the world. LAMP has been utilized to detect malaria parasites mainly using the conventional 18S ribosomal RNA (18S rRNA) gene as the target sequence $[6,12,16,23-27]$. In this study, we have developed and evaluated the LAMP technique for the detection of Plasmodium genus, Plasmodium falciparum and Plasmodium vivax from whole blood and dry blood spot.

\section{Methods}

\section{Samples}

All of samples used for positive control purposes were Whole Blood (WB) and Dry Blood Spot (DBS) from human infected with Plasmodium falciparum, Plasmodium vivax, Plasmodium malariae, Plasmodium ovale, and Plasmodium knowlesi. The samples were collected from human Gia Lai province, Vietnam. There were confirmed from WHO EQA program. There used DNA from Plasmodium as positive control and DNA from other parasites was also extracted to determine the specificity.

The use of the human and the collection of samples were approved by the bioethics committee of National Institute of Malariology, Parasitology and Entomology (NIMPE).

\section{DNA extraction protocol}

Using the QIAamp DNA microkit of Qiagen (Germany) extracted total DNA of Plasmodium species from $\mathrm{WB}$ and DBS samples. We followed the extraction procedure is performed according to the manufacturer's instructions.

\section{LAMP primer design}

Primers used for the LAMP assay were designed based on a highly conserved region of Plasmodium genus, Plasmodium falciparum, Plasmodium vivax genome. Genbank sequences (http://blast.ncbi.nlm.nih.gov/Blast.cgi) (Table 1) including the $18 \mathrm{~S}$ rRNA gene were tested in silico through BLAST searches and alignment analysis using the Clutal $\mathrm{W}$ module of MEGA 7 software, 521 base pairs, 437bp and 562 bp consensus sequences were seclected for the design of specific primers for Plasmodium genus, Plasmodium falciparum, Plasmodium vivax using Primer Explore V5 (http://primerexplorer.jp/lampv5e/ index.html).

Table 1: Genbank accession numbers for the different Plasmodium spp isolates included in the alignment.

\begin{tabular}{|c|c|c|}
\hline No & Isolates & Genbank accession number \\
\hline 1 & Plasmodium falciparum & MF155937 \\
\hline 2 & Plasmodium vivax & U83877 \\
\hline 3 & Plasmodium malariae & AF488000 \\
\hline 4 & Plasmodium ovale & L48987 \\
\hline 5 & Plasmodium knowlesi & DQ530263 \\
\hline
\end{tabular}

\section{Optimization of the assay}

PCR assay: The outer primers of the LAMP primer designed in this study (the F3 and B3 primers) were tested for their specificity in PCR assay. DNA from WB and DBS which comprised of P. falciparum, P. vivax, P. malariae, P. ovale, P. knowlesi were used as the DNA templates for the specificity test. A standard PCR, using $0.5 \mu \mathrm{M}$ of primers $\mathrm{F} 3$ and $\mathrm{B} 3$ and $2 \mu \mathrm{L}$ DNA, was carried out in the total volume of $20 \mu \mathrm{L}$ using HotstarTaq Plus Master Mix kit (Qiagen, Germany). The annealing temperature is $60^{\circ} \mathrm{C}$ for 30 seconds. PCR products were analysed by electrophoresis in $2 \%$ agarose TBE. All reactions were carried out in triplicate.

LAMP assay: There was set up testing different temperatures, $\mathrm{MgSO}_{4}$ concentrations, reaction time, visually detected dye concentrations. LAMP reaction mixtures $(25 \mu \mathrm{L})$ contained 1x Isothermal Amplification buffer (New England Biolabs, UK), $\mathrm{MgSO}_{4}$ (4, 6 or $8 \mathrm{mM}$ ) (New England Biolabs, UK), $1.4 \mathrm{mM}$ of each dNTPs (Qiagen, Germany), 5pmol of each F3 and B3 primers, 40pmol of each FIB and BIP primers, 20pmol of each LF and LB primers, and 8U of Bst 2.0 DAN polymerase (New England Biolabs, UK) with $5 \mu \mathrm{L}$ of DNA. Different temperatures were tested using a thermocycler (PCR gradient Nesux GX1, Eppendorf) set from $56^{\circ} \mathrm{C}$ to $65^{\circ} \mathrm{C}$ for 40 and 60 minutes and then $80^{\circ} \mathrm{C}$ for 5 minutes. Amplifications were visualy detected by adding Green Malachite at $0.012 \%, 0.008 \%, 0.004 \%$ and $0.001 \%$. Light blue was observed in successful LAMP reactions and colourless in negative reactions. LAMP reaction products were also analyzed by electrophoresis in $2 \%$ TBE agarose. All experiments were completed in all three times. 


\section{Preparation of Plasmodium genus, $P$. falciparum, $P$. vivax plasmid DNA templates}

For the detection and evaluation limits of estmate sensitivity, plasmids containing target regions of the rRNA $18 \mathrm{~S}$ gene were established for each species and calculated the copy number. The limit of detection (LOD) of LAMP assay was determined by using a ten-fold serial dilution of recombinant plasmid encompassing the target region of the 18S rRNA gene were constructed for all Plasmodium species, $P$. falciparum and $P$. vivax (from $10^{-6} \mathrm{ng} / \mu \mathrm{l}$ to $10^{-11} \mathrm{ng} / \mu \mathrm{L}$ ). The final dilutions were calculated following the formula as mentioned bellow for the corresponding copy number of the $18 \mathrm{~S}$ rRNA gene as a single copy gene.

The specific PCR primers for cloning were designed based on a highly specific region of the 18S rRNA genes of Plasmodium genus, P. falciparum, P.vivax. Then, genomic DNA was subsequently amplified by PCR, which produced the product 521, 437, 562 bp in size corresponding to Plasmodium genus, $P$. falciparum, P. vivax. After that, the PCR product was purified and cloned into pUC19 vector (Invitrogen, USA). Concentrations of recombinant plasmid DNA were measured with a Nanophotometer (IMPLEN, Germany), and corresponding copy numbers were calculated as mole multiplies of Avogadro's number using an online program (http://cels.uri.edu/gsc/ cndna.html), following the formula as the number of copies by amount $\times 6.022 \times 10^{23} /$ length $\times 10^{9} \times 650$.

\section{Clinical sample}

A total of 200 DBS samples were collected from Gia Lai provinces, Vietnam (between 2017-2018), All these clinical samples were evaluated by LAMP assay comparing with qPCR as gold standard test. The percentage of sensitivity, specificity was calculated in format of $2 \times 2$ cross-tabulation Table.

\begin{tabular}{|c|c|c|}
\hline \multirow{2}{*}{ LAMP in-house methode } & \multicolumn{2}{|c|}{ Gold standard testt } \\
\cline { 2 - 3 } & Positive & Negative \\
\hline Positive & TP & FP \\
\hline Negative & FN & TN \\
\hline Total & TP + FN & FP + TN \\
\hline
\end{tabular}

† $\mathrm{TP}=$ true positive., $\mathrm{FP}=$ false positive, $\mathrm{TN}=$ true negative, $\mathrm{FN}=$ false negative .

$$
\begin{aligned}
& \text { Sensitivity }(\%)=\frac{\mathrm{TP}}{\mathrm{TP}+\mathrm{FN}} \times 100 \\
& \text { Specipicity }(\%)=\frac{\mathrm{TN}}{\mathrm{FP}+\mathrm{TN}} \times 100
\end{aligned}
$$

In silico comparisions of LAMP primer sets showed a homology of $100 \%$ with Plasmodium genus, $P$. falciparum and $P$. vivax. The PCR specificity test using F3 and B3 primers of LAMP Primer amplified DNA from P. vivax, P. falciparum, P. malariae, P. ovale, and P. knowlesi with an amplicon length from 196 to $199 \mathrm{bp}$ for Plasmodium genus, 221bp for $P$. falciparum and $217 \mathrm{bp}$ for P. vivax (visualized by gel electrophoresis and UV detection). With $P$. falciparum and $P$. vivax no cross reactivity was observed with any of the tested simian malaria parasite species or with the malaria-negative human DNA control (Figure 1) Table 2.

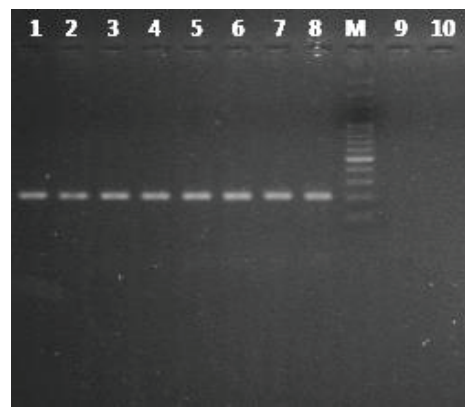

Figure 1a: PCR products using F3-B3 primers of Plasmodium genus: 1-2: $P$. falciparum; 3-4: P. vivax; 5-6: P. malariae; 7: P. ovale; 8: P. knowlesi.

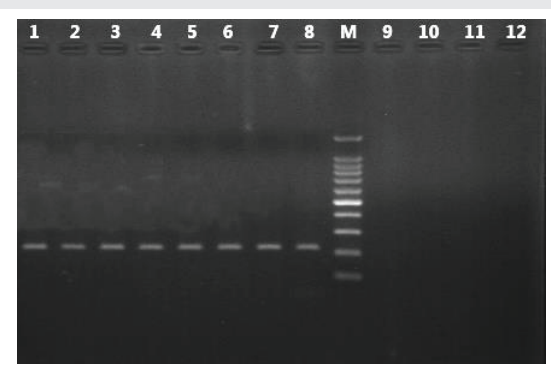

Figure 1b: PCR products using F3-B3 primers of $P$. falciparum: 1-8: $P$. falciparum; 9 : P. vivax; 10: P. malariae; 11: P. ovale; 12: P. knowlesi.

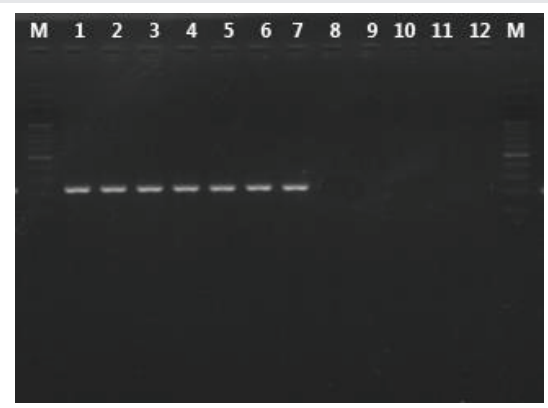

Figure 1c: PCR products using F3-B3 primers of $P$. vivax: 1-7: $P$. vivax; 8 : $P$. falciparum ; 9: P. malariae; 10: P. ovale; 11: P. knowlesi

Table 2: Nucleotide sequences of the LAMP primers targeting the 18sRNA gene.

\begin{tabular}{|l|l|l|}
\hline Primer sets & $\begin{array}{l}\text { Primer } \\
\text { name }\end{array}$ & Sequence \\
\hline Genus (PAN-LAMP) & F3 & GGCGCGTAAATTACCCAA \\
\hline & B3 & AGCGTTTTAACTGCAACAA \\
\hline & FIP & $\begin{array}{l}\text { CCATCATTCCAATTACAAAGCCAGA- } \\
\text { AGAAGAGAGGTAGTGACAAG }\end{array}$ \\
\hline & BIP & $\begin{array}{l}\text { AACCTTCCCAAAACTCAATTGGA- } \\
\text { TTTTAATATACGCTATTGGAGCT }\end{array}$ \\
\hline P. falciparum (Pf-LAMP) & F3 & GCAGCCGCGGTAATTCC \\
\hline & B3 & TATGGTTTTGTAATTGGAATGG \\
\hline FIP & CGCTATTGGAGCTGGAATTACC- \\
\hline AGAGTAACAATTGGAGGGC \\
\hline BIP & GTTGCAGTTAAAACGCTCGTAGTT- \\
\hline GAAAAGCTAAAATAGTTCCCCT
\end{tabular}


The data revealed that the reaction temperatures at $60^{\circ} \mathrm{C}$ (Plasmodium genus) and $63^{\circ} \mathrm{C}$ (P. falciparum and P. vivax) and the concentration of $\mathrm{MgSO}_{4} 8 \mathrm{mM}$ had highest LAMP amplification efficiency (Figure 2).

The optimum concentration of MG dye indicated that $0.004 \%$ MG was suitable for discrimination of the results as light blue and colourless in positive and negative reactions, respectively (Figure 3).

To determine the lower detection limit, 10-fold serial dilutions of each plasmid DNA were amplified. The detection limit for LAMP was 2,97 x 10-2 copies for P. falciparum and 2,85 copies for P. vivax, respectively. The amplification products were visualised on an agarose gel as a ladder of multiple bands. (Figure 4).

Although microscopic examination by Giemsa microscopy has been identified as the gold standard for the diagnosis of malaria parasites. But the detection threshold of this technique is from 20 to 100 parasites/ $1 \mu$ l of blood; much higher than the detection threshold of LAMP technique which is about 2-3 parasites/ $\mu \mathrm{l}$ of blood; If we compare these two techniques directly, the sensitivity will be very low such as Table 3 .

We therefore compared the results of the LAMP test with the qPCR technique, which has similar sensitivity and specificity Tables 4-6.

Total 95 positive samples and 105 negative samples base on qPCR were used. Of the 95 positives, 45 were positive for $\mathrm{P}$. falciparum, 43 were $P$. vivax positive and seven were positive for remaining Plasmodium spp. The sensitivity was $97.89 \%$, $97.78 \%$ and $97.67 \%$ for PAN-LAMP, Pf-LAMP and PvLAMP assay, respectively. The Specific was 97.14\%, 98.06\% and $97.45 \%$ for PAN-LAMP, Pf-LAMP and Pv-LAMP assay, respectively.

In 2019, Vietnam announced the elimination of malaria in 25 provinces, including 16 provinces in the north, 1 province
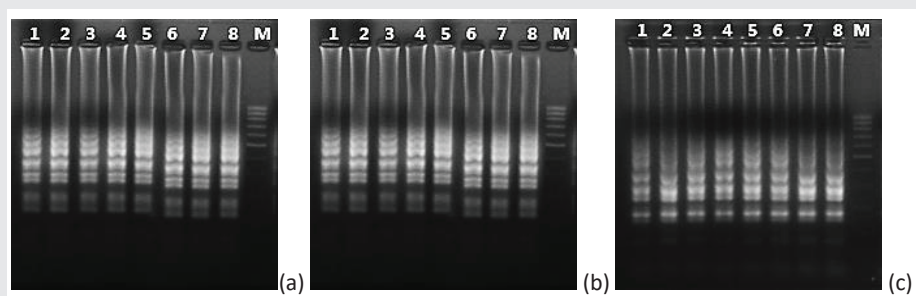

Figure 2: LAMP product at $63^{\circ} \mathrm{C}$ and $\mathrm{MgSO}_{4} 8 \mathrm{mM}$ of Plasmodium genus (a), $P$. falciparum (b) and P. vivax (c).

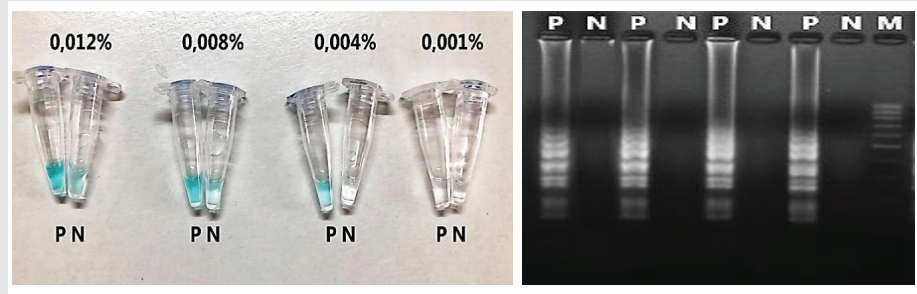

Figure 3: MG concentration tests at $0.012 \%, 0.008 \%, 0.004 \%$ and $0.001 \%$ at $63^{\circ} \mathrm{C}$ for $60 \mathrm{~min}$. $\mathrm{P}$ lane and $\mathrm{N}$ lane represent positive and negative reactions, respectively.
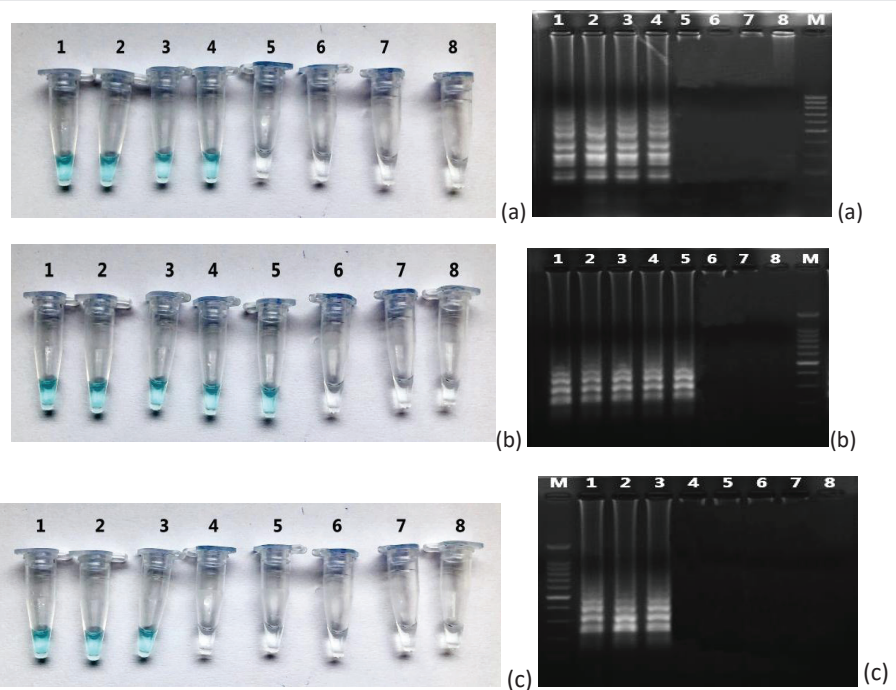

Figure 4: Detection limit of LAMP-MG assay of Plamodium genus (a); P. falciparum (b); P. vivax (c). 1-6: $10^{-6}$ to $10^{-11} \mathrm{ng} / \mu \mathrm{l} ; 7-8$ : negative control.

Detection limit of LAMP-2.0\% AGE of Plamodium genus (a); $P$. falciparum (b); $P$. vivax (c). 1-6: $10^{-6}$ to $10^{-11} \mathrm{ng} / \mu \mathrm{l} ;$ 7-8: negative control.

Table 3: Sensitivity and specificity of LAMP detect Plasmodium compared with GIEMSA stain.

\begin{tabular}{|c|c|c|}
\hline \multirow{2}{*}{ PAN-LAMP } & \multicolumn{2}{|c|}{ GIEMSA } \\
\cline { 2 - 3 } & Positive & Negative \\
\hline Positive & 58 & 105 \\
\hline Negative & 37 & 0 \\
\hline Total & 95 & 105 \\
\hline & Se: $61.05 \%$ & Sp: $100 \%$ \\
& $(\mathrm{Cl}: 50.50 \%-70.89 \%)$ & $(\mathrm{Cl}: 96.55-100 \%)$ \\
\hline
\end{tabular}

Table 4: Sensitivity and specificity of LAMP detect Plasmodium.

\begin{tabular}{|c|c|c|}
\hline \multirow{2}{*}{ PAN-LAMP } & \multicolumn{2}{|c|}{ qPCR } \\
\cline { 2 - 3 } & Positive & Negative \\
\hline Positive & 93 & 3 \\
\hline Negative & 2 & 102 \\
\hline Total & 95 & 105 \\
\hline & Se: $97.89 \%$ & Sp: $97.18 \%$ \\
& (Cl: $92.60 \%-99.74 \%)$ & (Cl: $91.88 \%-99.41 \%)$ \\
\hline
\end{tabular}

Table 5: Sensitivity and specificity of LAMP detect $P$. Falciparum.

\begin{tabular}{|c|c|c|}
\hline \multirow{2}{*}{ Pf-LAMP } & \multicolumn{2}{|c|}{ qPCR } \\
\cline { 2 - 3 } & Positive & Negative \\
\hline Positive & 44 & 3 \\
\hline Negative & 1 & 152 \\
\hline Total & 45 & 155 \\
\hline & Se: $97.78 \%$ & Sp: $98.06 \%$ \\
& $($ Cl: $88.23 \%-99.94 \%)$ & $(C .: 94.45 \%-99.60 \%)$ \\
\hline
\end{tabular}

Table 6: Sensitivity and specificity of LAMP detect $P$. Vivax.

\begin{tabular}{|c|c|c|}
\hline \multirow{2}{*}{ Pv-LAMP } & \multicolumn{2}{|l|}{ qPCR } \\
\hline & Positive & Negative \\
\hline Positive & 42 & 4 \\
\hline Negative & 1 & 153 \\
\hline \multirow[t]{2}{*}{ Total } & 43 & 157 \\
\hline & $\begin{array}{l}\text { Se: } 97.67 \% \\
\text { (Cl: } 87.71 \%-99.94 \%)\end{array}$ & $\begin{array}{l}\text { Sp: } 97.45 \% \\
93.61 \%-99.30 \%\end{array}$ \\
\hline
\end{tabular}

in the central and 8 provinces in the south. Vietnam's goal is to be recognized as a country eliminating malaria by 2030 [28]. To achieve this goal, the National Malaria Control 
Program of Vietnam has been implementing many appropriate strategies such as strengthening monitoring, detection, diagnosis and timely treatment. Every year in Viet Nam, the health system conducts tests of more than 2.2 million blood smears, nearly 500,000 rapid diagnostic tests for malaria [28]. The disadvantage of these two techniques is the low detection threshold. Therefore, it is estimated that a large number of people with low-density parasites are not detected. In areas where seasonal malaria is transmitted, people infected with low-density parasites below the detection threshold of blood smear and RDTs are both a regular source of transmission, but also a source of parasite storage through a low infectious season to a high infectious season [28]. Interventions with investigation and treatment to reducing malaria transmission have limited to rely on the detection of antigens using RDTs to identify asymptomatic cases of malaria patients.

Therefore, developing a test with high sensitivity, specificity and easy to do in the field is essential. Numerous studies have demonstrated that the LAMP technique is a highly specific, sensitive, short reaction time and allows the discovery of visual amplification products simply by observing turbidity, fluorescent dye or $\mathrm{pH}$ indicator dye. Herein, we have developed and evaluated the LAMP technique for the detection of Plasmodium genus, Plasmodium falciparum and Plasmodium vivax from whole blood and dry blood spot based on the $18 \mathrm{~S}$ rRNA gene.

We tested our assay specificity with all 5 species $P$.falciparum, $P$. vivax, $P$. malariae, $P$. ovale, $P$. knowlesi with satisfying results. However, our assay did not test another nonhuman malaria species. The nucleotide sequence analysis using the BLAST showed that no nonhuman malaria species were related to $\mathrm{P}$. falciparum and P. vivax primer sequences in this study (data not shown).

LAMP assay was carried out for 60 minutes and observed with the naked eye based on the color change in the tubes after amplification. In this study, we used MG as a color indicator dye. The color change of Malachite Green (cationic form) depends on the $\mathrm{pH}$ of the solution $(\mathrm{pH}<2$ : yellow, $\mathrm{pH}=3-9$ : blue, $\mathrm{pH}>10$ : colorless). Absorption wavelength for MG is 621 $\mathrm{nm}$. In the LAMP-MG assay, positive and negative samples that are easily distinguished by the naked eye with light blue and colorless, respectively. Using of $\mathrm{MG}$ as $\mathrm{pH}$-sensitive indicator dye for visual end-point assessment of LAMP products in various infections caused by bacteria [29], protozoa [13,15], and malaria [31] have been reported. Adding MG to LAMP buffer before conducting the reaction did not affect the activity of Bst DNA polymerase, while eliminating the risk of contamination between samples. The optimum concentration of MG used throughout this study was at $0.004 \%$, making positive and negative perfectly differentiated. The higher the MG concentration leads to an increase in false positive, the lower the MG concentration will not be able to distinguish between positive and negative samples. The blue color in the positive tubes still remains in color after the reaction for up to 6 weeks, at room temperature. Time after 6 weeks was not investigated in this study.
Recently, Loopamp ${ }^{\text {TM }}$ MALARIA Pan/Pf Detection Kit (Eiken Chemical) has become commercially available for the diagnosis of malaria by the LAMP method. This LAMP kit has good specificity and a lower detection limit of 25 parasites/ $\mu \mathrm{L}$ [13,31-34]. The detection limit of our LAMP methods for all Plasmodium species, $P$. falciparum and P. vivax was $2.89 \times 10^{-1}, 2.97$ $\times 10^{-2}$ and 2.85 copies/reaction, respectively (5 $\mathrm{LL}$ of sample DNA could be loaded per reaction). Therefore, the theoretical detection limit of the LAMP assay was equivalent to that of the previously described Loopamp ${ }^{\mathrm{TM}}$ MALARIA Pan/Pf and P.v Detection Kit.

The sensitivity and specificity of LAMP assay were evaluated with 200 clinical samples and used qPCR as a gold standard. The results show that the sensitivity and specificity of all assay are over $97 \%$, proving that the LAMP assay in this study has high sensitivity and specificity such as PCR and qPCR. However, PCR and real-time PCR methods require expensive equipments such as thermal cyclers or real-time PCR systems for accurate temperature control, expensive cost and difficult to apply in the field.

\section{Conclusion}

LAMP is a molecular method with high sensitivity and specificity. LAMP products are visible to the naked eye after the addition of the MG color indicator, which allows LAMP to be easily deployed in the field in medical facilities.

\section{Acknowledgments}

This study was supported by grants from National key scientific and technological project KC10 / 10.16-20.

\section{References}

1. Moody A (2002) Rapid Diagnostic Tests for Malaria Parasites. Clin Microbiol Rev 15: 66-78. Link: https://bit.ly/2P1Zth0

\section{2. (2020) National Malaria Control Progamme 2019 report. 80.}

3. WHO (2013) Proposal for an Evidence Review Group (ERG) on diagnosis of Plasmodium falciparum in low transmission areas. Briefing paper for the Malaria Policy Advisory Committee. Link: https://bit.ly/3g6oiEz

4. WHO (2015) World Malaria Report, Geneva, World Health Organization. Link: https://bit.ly/3f5JKrT

5. McMorrow M, Aidoo M, Kachur S (2011) Malaria rapid diagnostic tests in elimination settings-can they find the last parasite? Clin Microbiol Infect 17: 1624-1631. Link: https://bit.ly/332vzBC

6. Mohon AN, Getie S, Jahan N, Alam MS, Pillai DR (2019) Ultrasensitive loop mediated isothermal amplification (US-LAMP) to detect malaria for elimination. Malar J 18: 350. Link: https://bit.ly/2P2Zb90

7. Mohon AN, Lee LDY, Bayih AG, Folefoc A, Guelig D, et al. (2016) NINALAMP compared to microscopy, RDT, and nested PCR for the detection of imported malaria. Diagn Microbiol Infect Dis 85: 149-153. Link https://bit.ly/2WXpl1Z

8. Wongsrichanalai C, Barcus MJ, Muth S, Sutamihardja A, Wernsdorfer WH (2007) A review of malaria diagnostic tools: microscopy and rapid diagnostic test (RDT). Am J Trop Med Hyg 77: 119-127. Link: https://bit.ly/2DeiGJy

9. Mens P, Spieker N, Omar S, Heijnen M, Schallig H, et al. (2007) Is molecular biology the best alternative for diagnosis of malaria to microscopy? ADN comparison between microscopy, antigen detection and molecular tests 
in rural Kenya and urban Tanzania. Trop Med Int Health 12: 238-244. Link: https://bit.ly/2WZIhOv

10. WHO/HTM/GMP/2014.7 (2014) Policy brief on malaria diagnostics in lowtransmission setting. Link: https://bit.ly/306DiwE

11. Milne L, Kyi M, Chiodini P, Warhurst D (1994) Accuracy of routine laboratory diagnosis of malaria in the United Kingdom. J Clin Pathol 47: 740-742. Link: https://bit.ly/39yz5jk

12. Poschl B, Waneesorn J, Thekisoe O, Chutipongvivate S, Karanis P (2010) Comparative diagnosis of malaria infections by microscopy, nested PCR, and LAMP in northern Thailand. Am J Trop Med Hyg 83: 56-60. Link: https://bit.ly/39D2Bt5

13. Snounou G, Viriyakosola S, Zhua XP, Jarraa W, Pinheirob L, et al. (1993) High sensitivity of detection of human malaria parasites by the use of nested polymerase chain reaction. Mol Biochem Parasitol 61: 315-320. Link: https://bit.ly/30WjJWX

14. Wu L, Lotus LH, Hannah S, Walker PGT, Ghani AZC, et al. (2015) Coparison of diganostics for dectection of asymtomatic Plasmodium falciparum infections to inform control and elimination strategies. Nature 528: S86-93. Link: https://bit.ly/2P3rzbK

15. Notomi T, Okayama H, Masubuchi H, Yonekawa T, Watanabe K, et al. (2000) Loop-mediated isothermal amplification of DNA. Nucleic Acids Res 28: E63. Link: https://bit.ly/2Da1Prq

16. Han ET, Watanabe R, Sattabongkot J, Khuntirat B, Sirichaisinthop J, et al (2007) Detection of four Plasmodium species by genus- and species-specific loopmediated isothermal amplification for clinical diagnosis. J Clin Microbiol 45 2521-2528. Link: https://bit.ly/2X2KUOE

17. Hopkins H, González IJ, Polley SD, Angutoko P, Ategeka J, et al. (2013) Highly sensitive detection of malaria parasitemia in a malaria-endemic setting performance of a new loop-mediated isothermal amplification kit in a remote clinic in Uganda. J Infect Dis 208: 645-652. Link: : https://bit.ly/2EsbUAL

18. Patel JC, Oberstaller J, Xayavong M, Narayanan J, DeBarry JD, et al. (2013) Real-Time Loop-Mediated Isothermal Amplification (RealAmp) for the Species-Specific Identification of Plasmodium vivax. Plos one J 8: e54986. Link: https://bit.ly/30RuTfz

19. Lucchi NW, Gaye M, Diallo MA, Goldman IF, Ljolje D, et al. (2016) Evaluation of the illumigene malaria LAMP: a robust molecular diagnostic tool for malaria parasites. Sci Rep 6: 36808. Link: https://bit.ly/3jNRLVO

20. Perera RS, Ding XC, Tully F, Oliver J, Bright N, et al. (2017) Development and clinical performance of high throughput loop-mediated isothermal amplification for detection of malaria. PLoS One12: e0171126. Link: https://bit.ly/3f6YTt5

21. Polley SD, González IJ, Mohamed D, Daly R, Bowers K, et al. (2013) Clinical evaluation of a loop-mediated amplification kit for diagnosis of imported malaria. J Infect Dis 208: 637-644. Link: https://bit.ly/30ankSd

22. Rypien C, Chow B, Chan W, Church D, Pillai DR (2017) Detection of Plasmodium spp. infection by the illumigene malaria assay compared to reference microscopy and real-time PCR. J Clin Microbiol 55: 3037-3045. Link: https://bit.ly/332sRM7

23. Chen JH, Lu F, Lim CS, Kim JY, Ahn HJ, et al. (2010) Detection of Plasmodium vivax infection in the Republic of Korea by loop-mediated isothermal amplification (LAMP). Acta Trop 113: 61-65. Link: https://bit.ly/3g7Xh3g

24. Imai K, Tarumoto N, Misawa K, Runtuwene LR, Sakai J, et al. (2017) A novel diagnostic method for malaria using loop-mediated isothermal amplification
(LAMP) and MinION ${ }^{\mathrm{TM}}$ nanopore sequencer. B BMC Infect Dis 17: 621. Link: Link: https://bit.ly/39z4JC5

25. Ling LY, Lai MY, Fong MY, Jelip J, Mahmud R (2016) Loop-Mediated Isotherma Amplification Assay for Identification of Five Human Plasmodium Species in Malaysia. Am J Trop Med Hyg 94: 336-339. Link: https://bit.ly/2X0gVXK

26. Paris DH, Imwong M, Faiz AM, Hasan M, Yunus EB, et al. (2007) Loopmediated isothermal PCR (LAMP) for the diagnosis of falciparum malaria. Am J Trop Med Hyg 77: 972-976. Link: https://bit.ly/3hGltdC

27. Poon LL, Wong BW, Ma EH, Chan KH, Chow LM, et al. (2006) Sensitive and inexpensive molecular test for falciparum malaria: detecting Plasmodium falciparum DNA directly from heat-treated blood by loop-mediated isothermal amplification. Clin Chem 52: 303-306. Link: https://bit.ly/3jMrxD9

28. WHO (2018) National Malaria Programme Review - VietNam. Link: https://bit.ly/3hNVKjD

29. Farnia P, Masjedi MR, Mohammadi F, Tabarsei P, Farnia P, et al (2008) Colorimetric detection of multidrugresistant or extensively drug-resistant tuberculosis by use of malachite green indicator dye. J Clin Microbiol 46 796-799. Link: https://bit.ly/3f3XHGz

30. Lucchi NW, Ljolje D, Silva-Flannery L, Udhayakumar V (2016) Use of malachite green-loop mediated isothermal amplification for detection of Plasmodium spp. parasites. PLoS One 11: e0151437. Link: https://bit.ly/3hMBD5j

31. Falade CO, Ajayi IO, Nsungwa-Sabiiti J, Siribié M, Diarra A, et al. (2016) Malaria rapid diagnostic tests and malaria microscopy for guiding malaria treatment of uncomplicated fevers in Nigeria and prereferral cases in 3 African countries. Clin Infect Dis 63: S290-297. Link: https://bit.ly/3hIFwbe

32. Nzelu CO, Cáceres AG, Guerrero-Quincho S, TineoVillafuerte E, RodriquezDelfin L, et al. (2016) A rapid molecular diagnosis of cutaneous leishmaniasis by colorimetric malachite green-loop-mediated isothermal amplification (LAMP) combined with an FTA card as a direct sampling tool. Acta Trop 153 116-119. Link: https://bit.ly/2CTNjnV

33. Sriworarat C, Phumee A, Mungthin M, Leelayoova S, Siriyasatien P (2015) Development of loop-mediated isothermal amplification (LAMP) for simple detection of Leishmania infection. Parasit Vectors 8: 591. Link: https://bit.ly/302RMNM

34. WHO (2019) World Malaria Report, Geneva, World Health Organization. Link: https://bit.ly/3hIE7I7

\section{Discover a bigger Impact and Visibility of your article publication with}

\section{Peertechz Publications}

\section{Highlights}

* Signatory publisher of ORCID

* Signatory Publisher of DORA (San Francisco Declaration on Research Assessment)

* Articles archived in worlds' renowned service providers such as Portico, CNKI, AGRIS, TDNet, Base (Bielefeld University Library), CrossRef, Scilit, J-Gate etc.

* Journals indexed in ICMJE, SHERPA/ROMEO, Google Scholar etc.

* OAI-PMH (Open Archives Initiative Protocol for Metadata Harvesting)

* Dedicated Editorial Board for every journa

* Accurate and rapid peer-review process

* Increased citations of published articles through promotions

* Reduced timeline for article publication

Submit your articles and experience a new surge in publication services (https://www.peertechz.com/submission).

Peertechz journals wishes everlasting success in your every endeavours.

Copyright: (c) 2020 Hong Ngoc NT, et al. This is an open-access article distributed under the terms of the Creative Commons Attribution License, which permits unrestricted use, distribution, and reproduction in any medium, provided the original author and source are credited.

Citation: Hong Ngoc NT, Huong Binh NT, Hong NV, Thang ND, Huong NT, et al. (2020) In-house validation of a lamp kit for diagnosis of Plasmodium, Plasmodium falciparum and Plasmodium vivax in Vietnam. Glob J Infect Dis Clin Res 6(1): 048-053. DOI: https://doi.org/10.17352/2455-5363.000035 